\title{
Cartografia Materna: a experiência da forma enquanto discurso no livro-objeto
}

Mateus Guimarães Meireles

\section{Resumo}

Com o objetivo de promover a reflexão sobre o papel da materialidade no processo de construção do discurso em um livro-objeto, esclarecendo a trajetória e aspectos dessa vertente artística, esse artigo revisita a criação da obra Cartografia Materna. O objeto de estudo é fruto da experimentação das linguagens verbal e não verbal em instalações e perfis jornalísticos.

\section{Palavras-chave}

Livro-objeto; forma; discurso; reconfiguração; interação.

A proposta do projeto "Cartografia Materna" é, partindo da estrutura rizomática, experimentar a linguagem verbal e não verbal na construção de quatro livros-objetos, constituídos por perfis jornalísticos e instalações artísticas. As perfiladas são exclusivamente mães com as quais tive contato através de diários escritos pelas mesmas. 
Do primeiro esboço ao término do projeto, procurei empregar o conceito de rizoma, cunhado por Deleuze e Guattari (1995). Os pesquisadores propõem um sistema epistemológico não hierárquico de partes igualmente importantes e infinitamente ramificáveis, inspirado no comportamento do caule de algumas plantas. Levando esse arranjo para o trabalho, me dispus a apresentar discursos fragmentados em constante relação, reconfigurados a cada experiência. Algo sempre "(...) desmontável, conectável, reversível". (DELEUZE e GUATTARI, 1995, p.33).

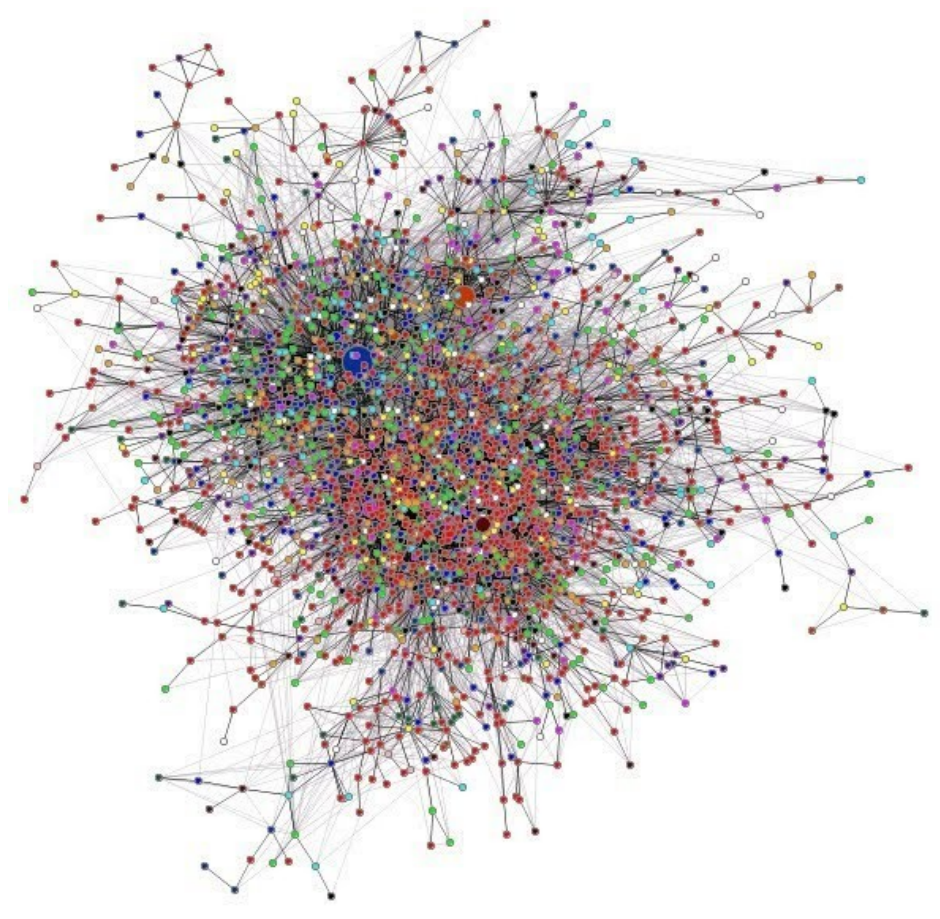

Figura 1: Representação de um rizoma

Fonte: <http://www.rizoma.milharal.org/2012/07/14/a-tirania-das-organizacoes-sem-estrutura/ > acesso em 8 de outubro de 2014

Esse arranjo me inspirou a utilizar o livro de artista, que se destaca por demandar uma leitura mais interpretativa e apresentar grande apelo estético.

(...) em todas as suas formas clama pelo conhecimento através dos sentidos e da razão, exigindo reflexão e uma decifração dos elementos à disposição, revelando ao observador um artista para além das palavras (ALMEIDA, 2012, p.36). 
Dentro desse grupo, propus um outro recorte, me enveredando para o livro-objeto. Apesar de comungar características gerais, ele carrega suas especificidades. A preocupação estética é ainda mais evidente, especialmente ao considerar o talhe, que é equiparado ao conteúdo e o modifica, construindo de forma conjunta sentido no momento da interpretação. Não há dissociação do verbal e do não verbal.

O livro-objeto quebra totalmente com a forma tradicional do livro assumindo-se como uma obra de arte única. No entanto continua com fortes ligações ao conceito de livro em si dado que postula uma leitura, quer literária quer interpretativa. O caráter literário aparece habitualmente através das palavras, frases ou pequenos textos, ao passo que a leitura interpretativa comporta sobretudo o próprio material utilizado na confecção do livro em junção com a forma que se apresenta ao observador (ALMEIDA, 2012, p.45).

A produção dos quatro exemplares englobou ao mesmo tempo a concepção das formas e conteúdos, mantendo fidelidade à sua proposta original. Foram criados dez textos com suportes variados, três colagens digitais que foram inseridas em monóculos, três intervenções digitais em fotografias que vieram com os diários, uma intervenção no interior da tampa da caixa e uma garrafa com fios de cabelo do filho de uma das perfiladas. $O$ exterior do estojo foi envolto em uma trama de barbante branco. A ideia era evocar as conexões do rizoma logo no primeiro contato com o produto e demandar interação para o manuseio do livro-objeto.

A busca pelo tema do projeto "Cartografia Materna" veio da predileção que tenho desde pequeno por documentos e objetos antigos. Passava horas me aventurando pelos grandes armários de madeira da casa de minha avó paterna. Mesmo miúdo, a imponência desses móveis não me coagia, os escalava com desembaraço ímpar. Ciente de que, caso fosse pego, o castigo seria certo. As expedições exploratórias revelavam a arqueologia de uma família: um cavalo marinho seco dentro de uma caixa de plástico, o anel que meu pai 
ganhou na sua formatura em Engenharia, cartas trocadas com familiares e anotações pessoais de vovó.

Desejava fazer essa viagem novamente, mas, dessa vez, nas entranhas de outra linhagem. Comecei uma busca em sebos e antiquários de Belo Horizonte e na internet. Em uma lojinha apertada e escondida do segundo andar do Conjunto Arcangelo Maletta, encontrei um senhor que abria o seu estabelecimento dia sim, dia não. Ele se dividia entre o modesto comércio em $\mathrm{BH}$ e o seu depósito em Juatuba. De lá, depois de dias de espera, que pareceram anos, ele trouxe uma caixa empoeirada repleta de relíquias. Em meio aos espirros, percebi que passagens da vida de muitas pessoas cabiam naquele papelão malajambrado. Mas um diário me chamou mais a atenção. Nele, Maria do Carmo Rodrigues Maranhão contava a sua história e a do filho Caurobert de Albuquerque Maranhão durante os primeiros anos de vida do pequeno na capital do Rio de Janeiro. A forma como ela se inseria na narrativa e o carinho com que intervinha nas páginas fez com que eu voltasse para casa com esses registros. 

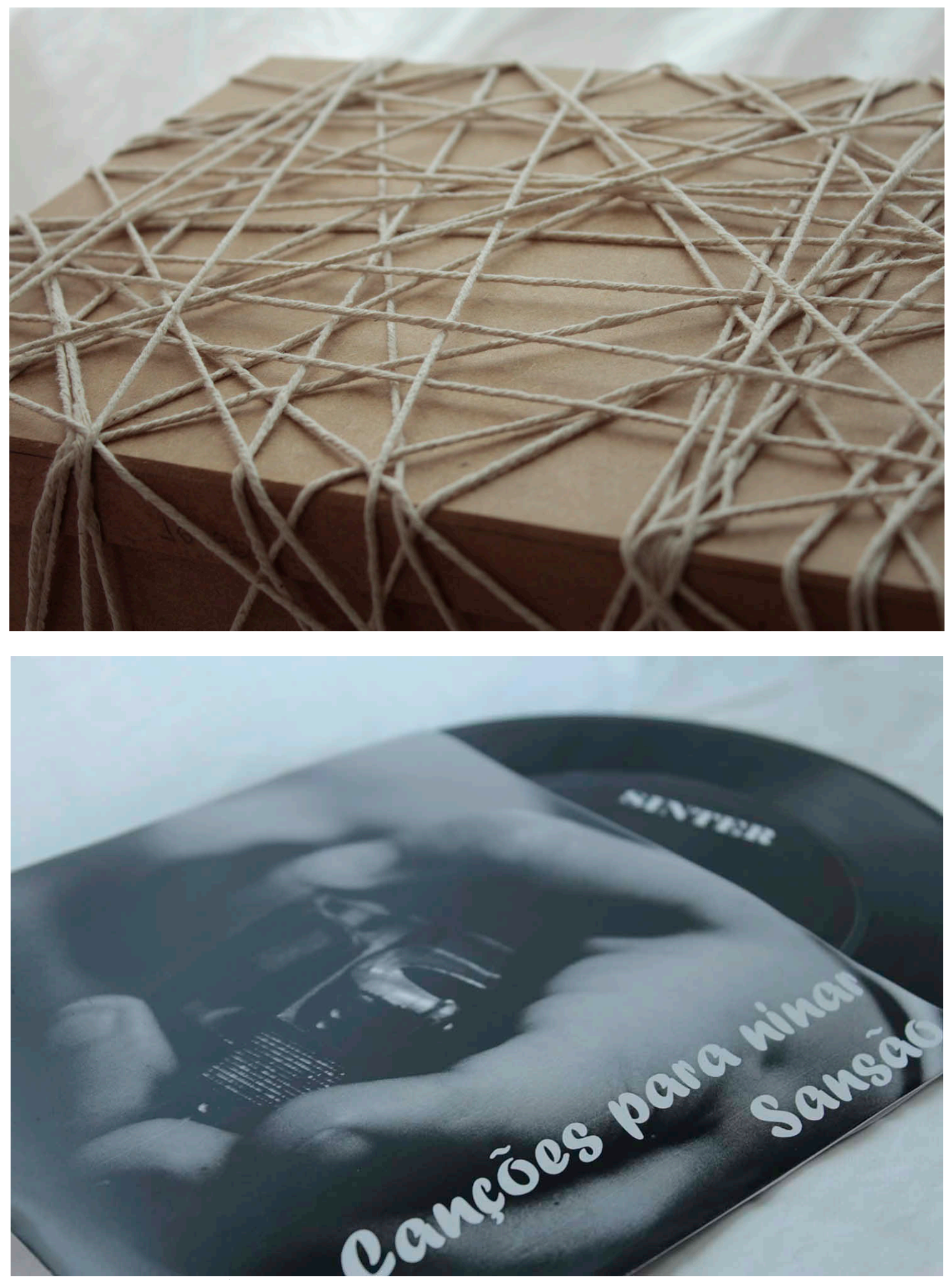

Figuras 2 e 3: detalhes do livro-objeto Cartografia Materna Fonte: Elaboração do autor 

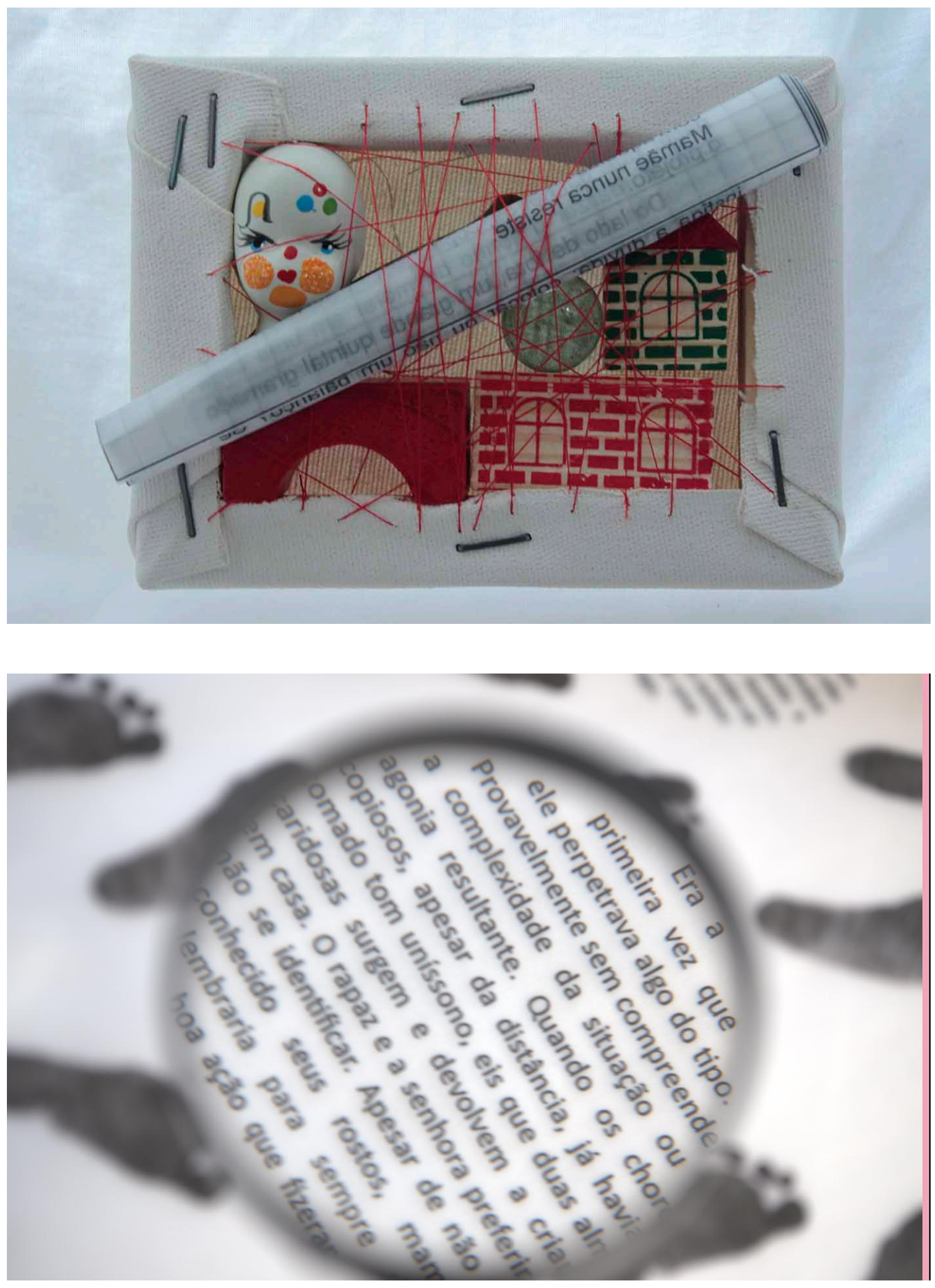

Figuras 4 e 5: detalhes do livro-objeto Cartografia Materna Fonte: Elaboração do autor 


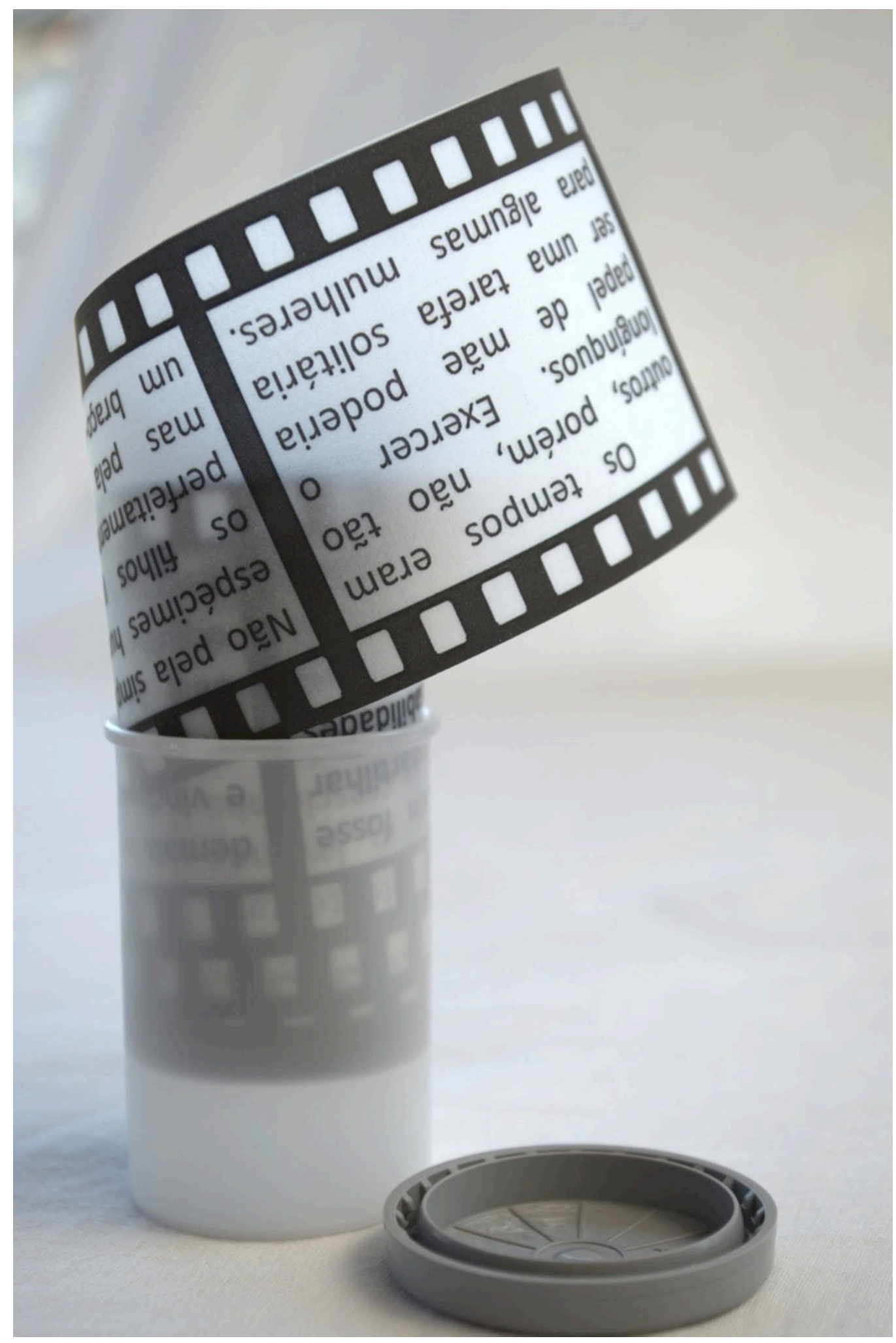

Figura 6: detalhe do livro-objeto Cartografia Materna Fonte: Elaboração do autor 


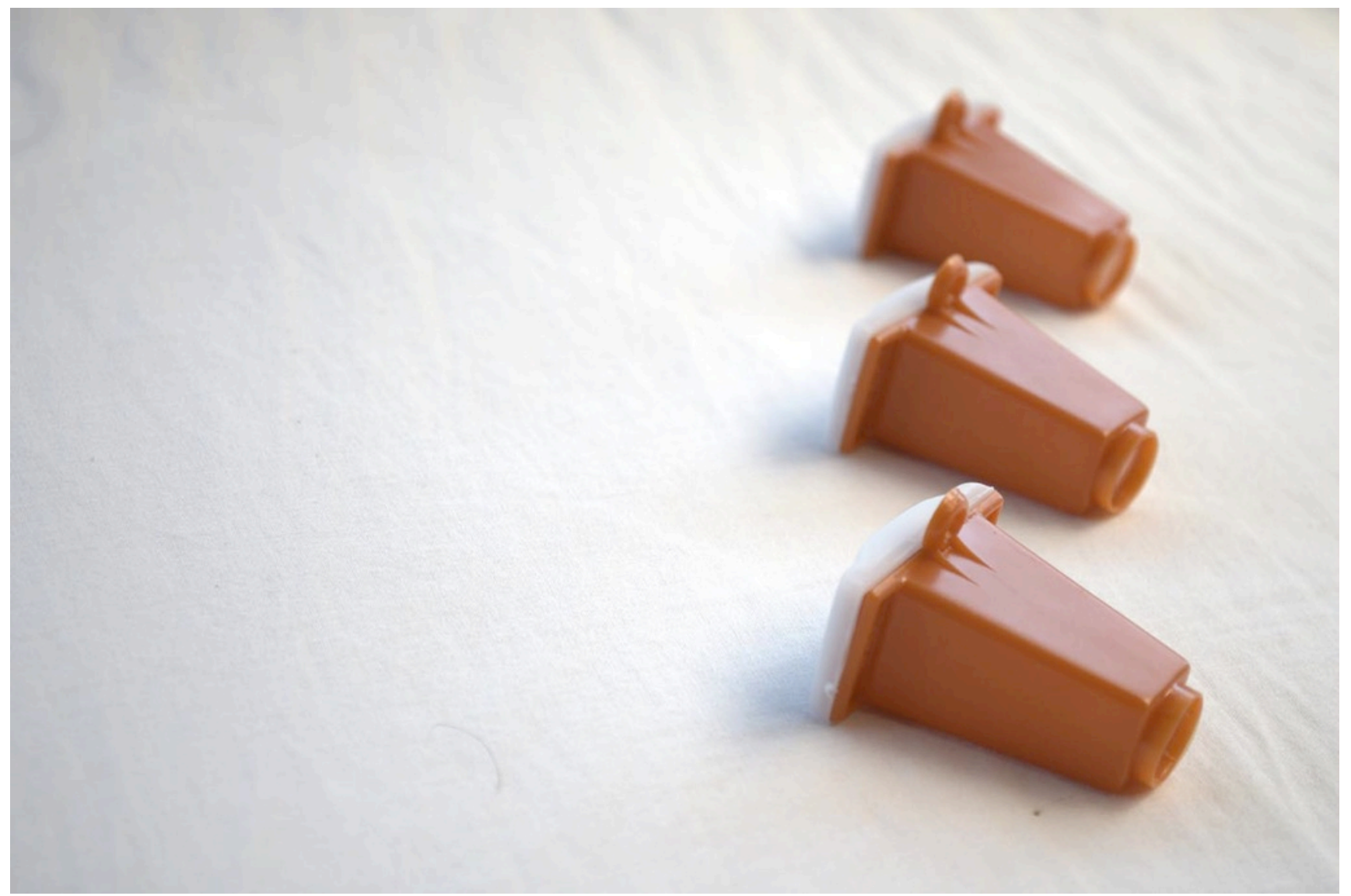

Figura 7: detalhe do livro-objeto Cartografia Materna

Fonte: Elaboração do autor

O segundo diário, na verdade, me encontrou. Estava navegando pela internet quando descobri no Mercado Livre o perfil do dono de um antiquário em Ribeirão Preto, São Paulo. Uma capa com aspecto aquarelado retratando uma mãe e seu filho sob a luz do sol me conquistou. Precisava saber o que constava em suas folhas. Depois de alguns emails trocados, pagamento do boleto e semanas de espera, a entrega. Ou quase, o vendedor havia colocado o meu endereço errado e o material quase voltou para o remetente. Vencidas as questões burocráticas nos Correios, pude, enfim, "fazer parte" de mais uma família, a de Vera Gaetani. Em um diário dedicado ao filho mais velho, Luiz Emanuel, ela conta sobre sua vida, crenças e como se esforçou para criar o menino e seus irmãos. A letra, 
METAgraphias: letra A de antiarte -ou- viva à vida v.1 n.2 junhol2016

às vezes confusa, era um convite para decifrar esse enigma. 


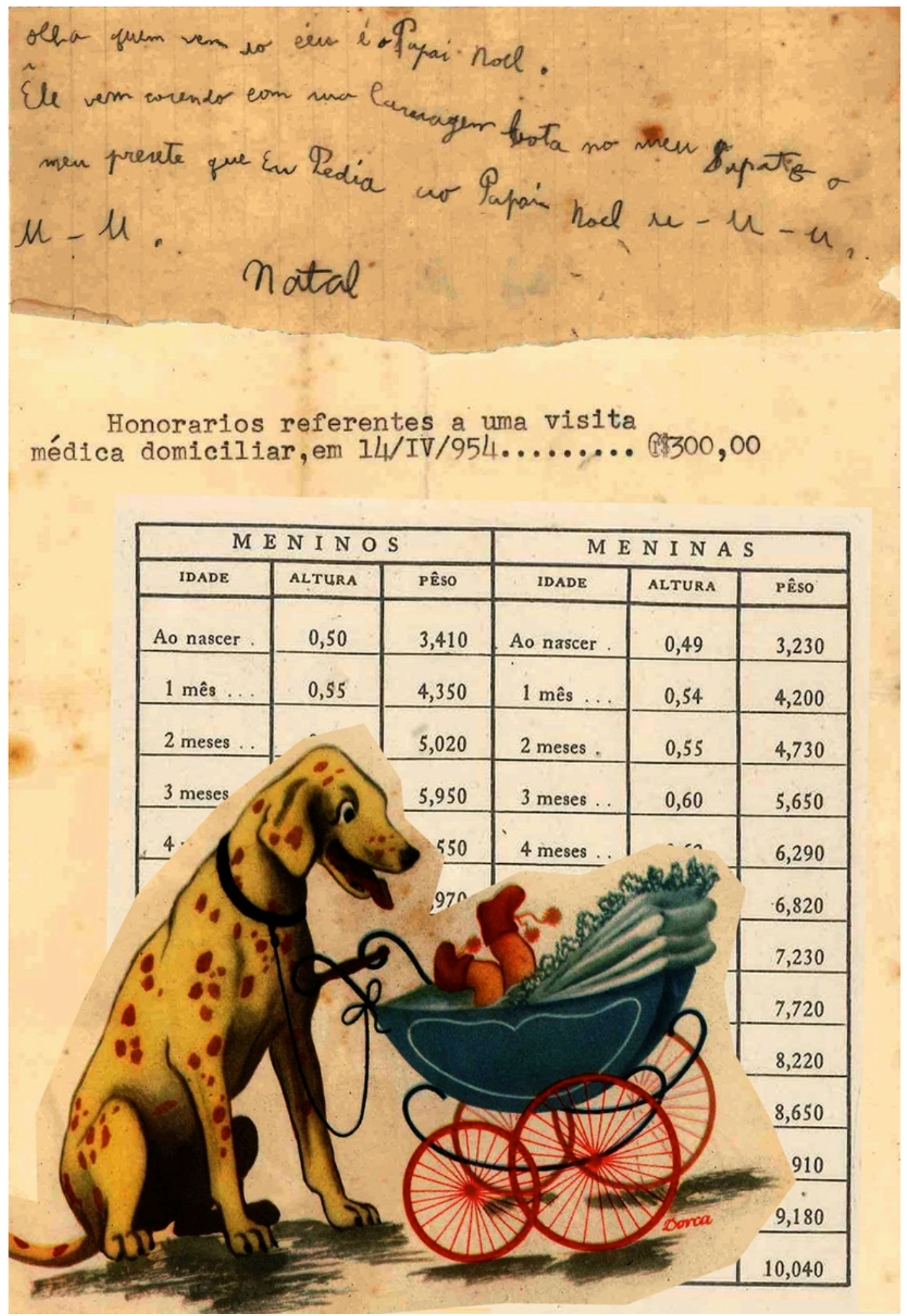

Figura 8: detalhe do livro-objeto Cartografia Materna

Fonte: Elaboração do autor 
A escolha por dois diários com a temática materna não foi aleatória. Na verdade, ela diz muito sobre mim. Enquanto jornalista, percorro a vida em busca de temas que me toquem, mesmo que sejam para incomodar. Tenho a necessidade de transformar essas emoções em carne, em músculo pulsante, por meio da escrita. Vim de uma família de mulheres protagonistas e isso sempre foi motivo de orgulho. Minha avó paterna ficou viúva cedo, teve um filho com um homem casado e sustentou sozinha a família sob julgamentos alheios. A materna se separou em uma época em que isso não era comum e, sem apoio do ex-marido, batalhou vendendo cosméticos para alimentar seus seis filhos. Por fim, minha mãe, que teve coragem de trazer ao mundo uma criança aos dezoito anos, casar-se, descobrir traições depois de quase uma década de convivência e partir em busca de uma vida que realmente Ihe completasse, sem momento algum pensar em deixar o filho para trás.

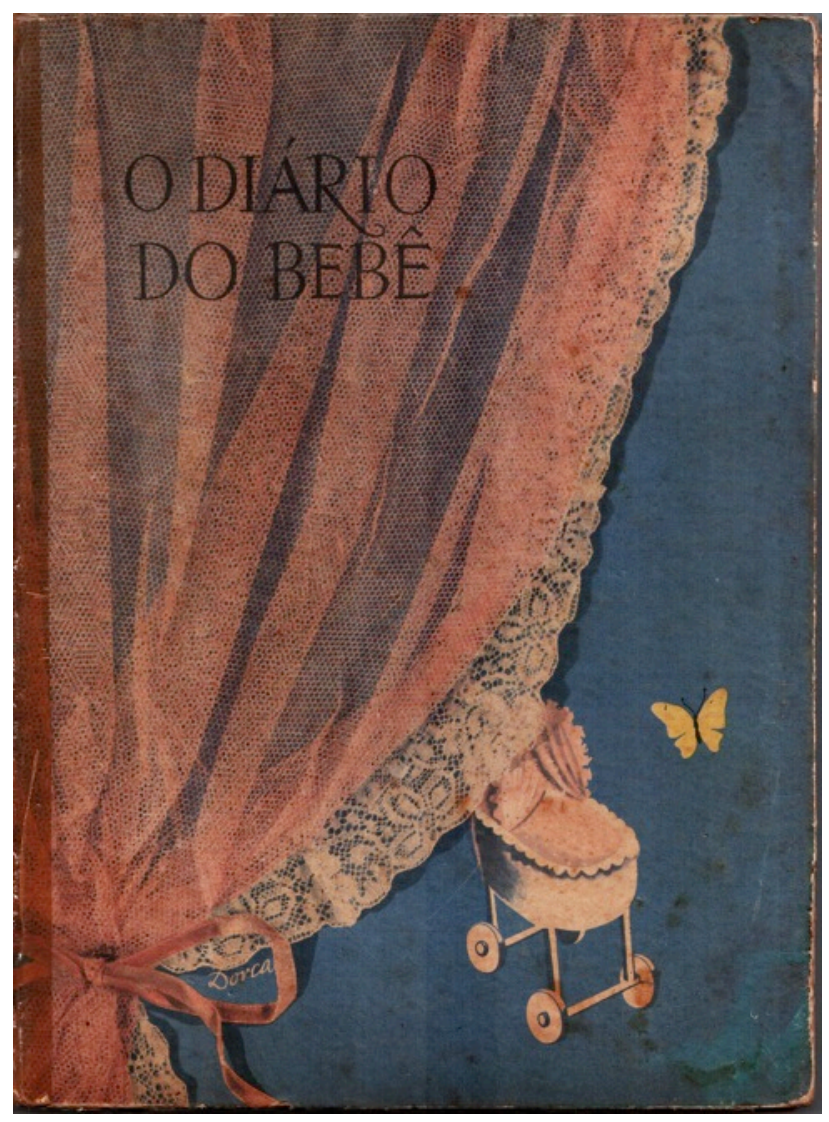


Figura 9: Diário 1

Fonte: Elaboração do autor

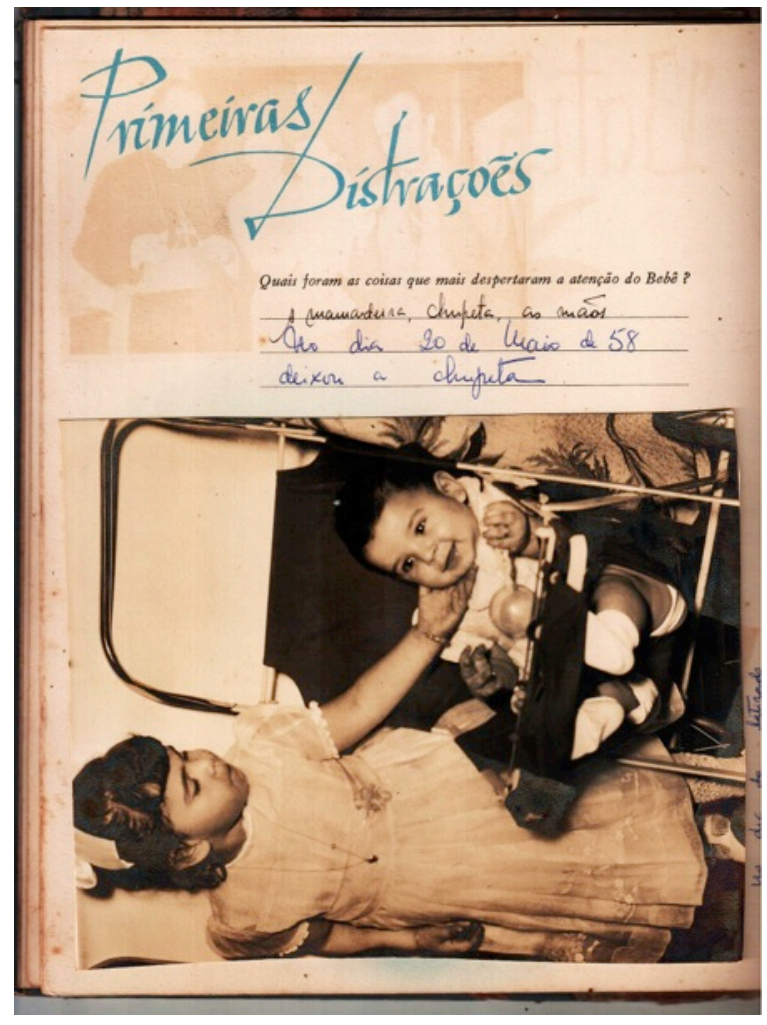

Figura 10: Diário 1

Fonte: Elaboração do autor 
METAgraphias: letra A de antiarte -ou- viva à vida v.1 n.2 junhol2016

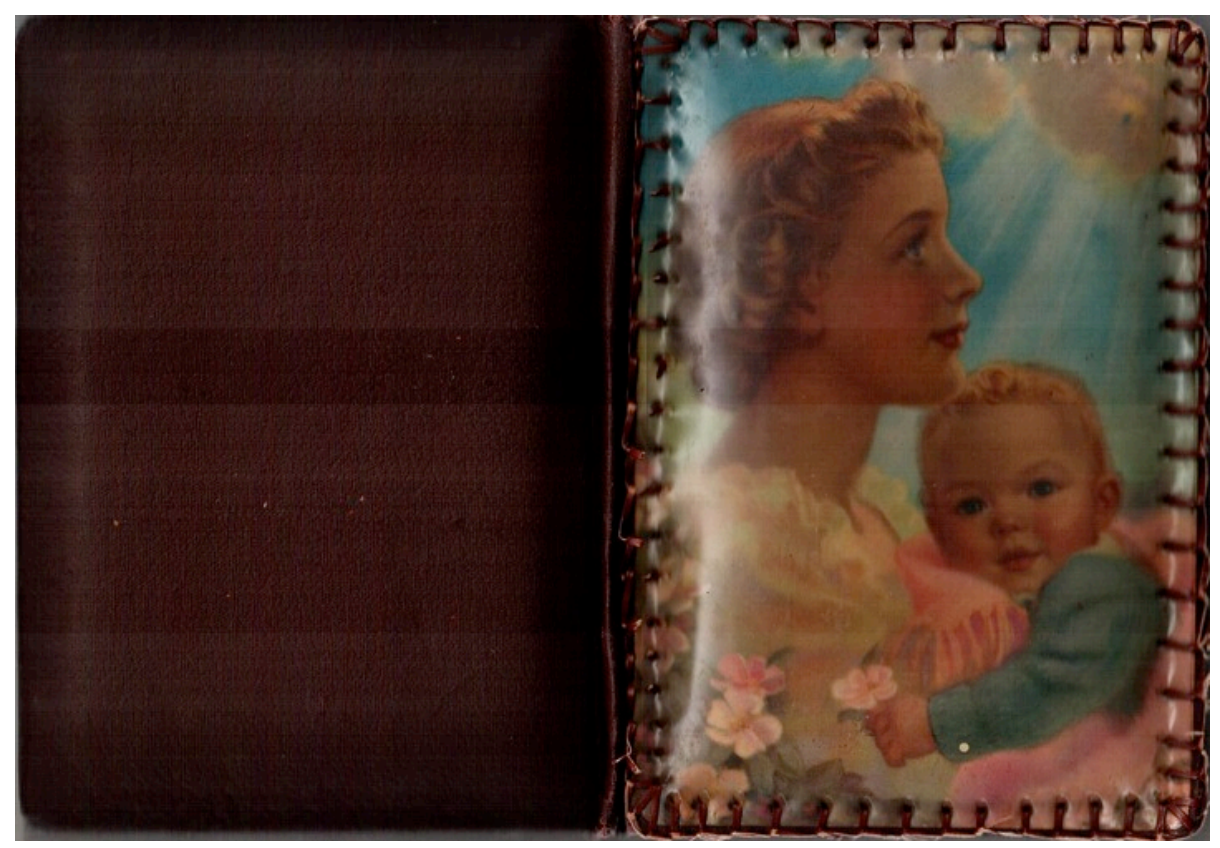

Figura 11: Diário 2

Fonte: Elaboração do autor 


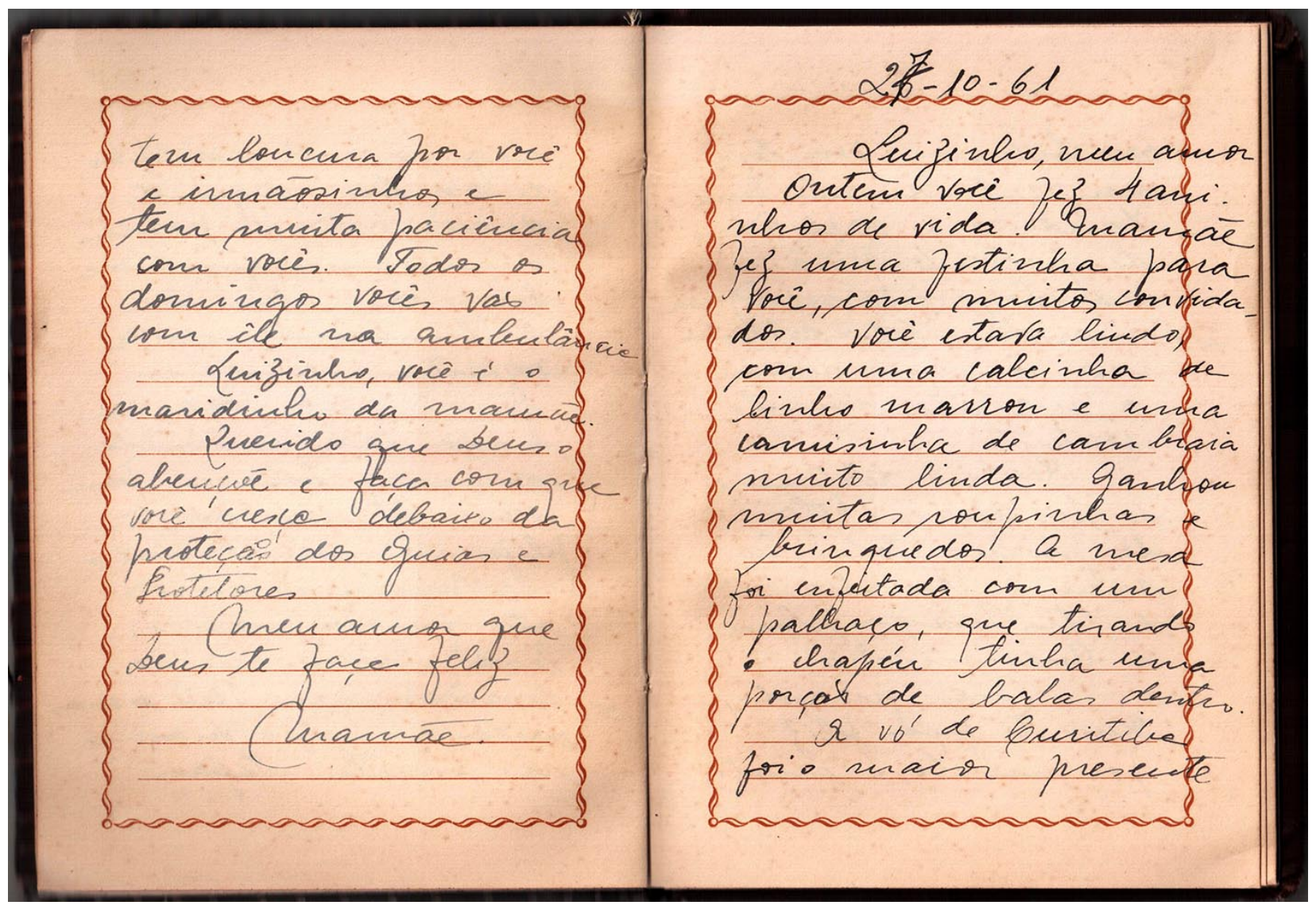

Figura 12: Diário 2

Fonte: Elaboração do autor

\section{A forma enquanto discurso}

Fala-se da dificuldade entre forma e conteúdo, em matéria de escrever; até se diz: o conteúdo é bom, mas a forma não, etc. Mas, por Deus, o problema é que não há de um lado um conteúdo, e de outro a forma. Assim seria fácil: seria como relatar através de uma forma o que já existisse livre, o conteúdo. Mas a luta entre a forma e o conteúdo está no próprio pensamento: o conteúdo luta por se formar. Para falar a verdade, não se pode pensar num conteúdo sem sua forma. Só a intuição é a funda reflexão inconsciente que prescinde de forma enquanto ela própria, antes de subir à tona, se trabalha. Parece-me que a forma já aparece quando o ser todo está com um conteúdo maduro, já que se quer dividir o pensar e escrever em duas fases. A dificuldade de forma está no próprio constituir-se do conteúdo, no próprio pensar ou sentir, que não saberia existir sem sua forma adequada e às vezes única (LISPECTOR, 
1999, p.271).

O suporte que um texto recebe pode declarar muito sobre a sua fruição. $\bigcirc$ arranjo de sua apresentação dá ao leitor indícios das escolhas para sua confecção e objetivos. Ele não pode ser analisado como elemento isolado do discurso e sim como parte de um todo. Chartier (2002) endossa essa perspectiva.

Os textos não existem fora dos suportes materiais (sejam eles quais forem) de que são veículos. Contra a abstração dos textos, é preciso lembrar que as formas que permitem sua leitura, sua audição ou sua visão participam profundamente da construção de seus significados. O "mesmo" texto, fixado em letras, não é o "mesmo" caso mudem os dispositivos de sua escrita e de sua comunicação (CHARTIER, 2002, p.61).

O autor exemplifica essa situação trilhando uma breve análise sobre a criação da Biblioteca Azul na França. Entre os séculos XVI e XVII, editores da região de Champagne tiveram a ideia de reaproveitar caracteres e utilizar papéis de qualidade inferior para publicarem livros de baixo custo, muitos deles encapados de papel azul.

Corretores eram contratados para fazer as modificações necessárias de acordo com os costumes ideológicos da época (censura de termos escatológicos ou pornográficos) e rearranjo da capitulação e extensão das obras. Essa situação tem valor especial para a pesquisa. Ela demonstra a importância do suporte na comunicação do texto.

O material utilizado na fabricação e as intervenções feitas na redação dos livros modificam o contato com a mensagem. Um exemplar da Biblioteca Azul não é o mesmo exemplar de outra editora. Ele possui suas especificidades e caracteriza uma sociedade que aos poucos passara a ter contato com a leitura, antes restrita aos clérigos e nobres.

Esse exemplo é um recorte da editoração tradicional. Para o livro "Cartografia Materna", optei por um sustentáculo que me permitisse aprofundar ainda mais na interferência da 
forma no conteúdo. O livro-objeto é uma das subdivisões de uma classe maior denominada livro de artista.

Essa escolha não foi por acaso. O livro de artista provém de vários momentos históricos e tradicionais do feitio de livros. Os primeiros manuscritos iluminados, os papiros egípcios e os pergaminhos japoneses e chineses já anunciavam a possibilidade de realçar e completar textos com elementos ornamentais e manufaturados.

O livro de artista em todas as suas formas clama pelo conhecimento através dos sentidos e da razão, exigindo reflexão e uma decifração dos elementos à disposição, revelando ao observador um artista para além das palavras. Na verdade, um livro com estas características não pode estar sujeito a limitações que impeçam ou deteriorem a mensagem. Verificando-se uma correlação simbiótica entre o conteúdo e o que contém (ALMEIDA, 2012, p.36).

Várias obras influenciaram o surgimento desse estilo, mesmo não sendo propriamente exemplares de livro do artista. São projetos de caráter vanguardista. Entre eles está a "caixa verde" de Marcel Duchamp, criada de 1912 a 1923 para traduzir verbo-imageticamente a concepção de "O Grande Vidro", pintura a óleo sobre uma placa de vidro duplo dividido em duas seções. A parte superior chamada "A noiva desnudada pelos seus celibatários, mesmo"; e a inferior, "Moinho de chocolate". 


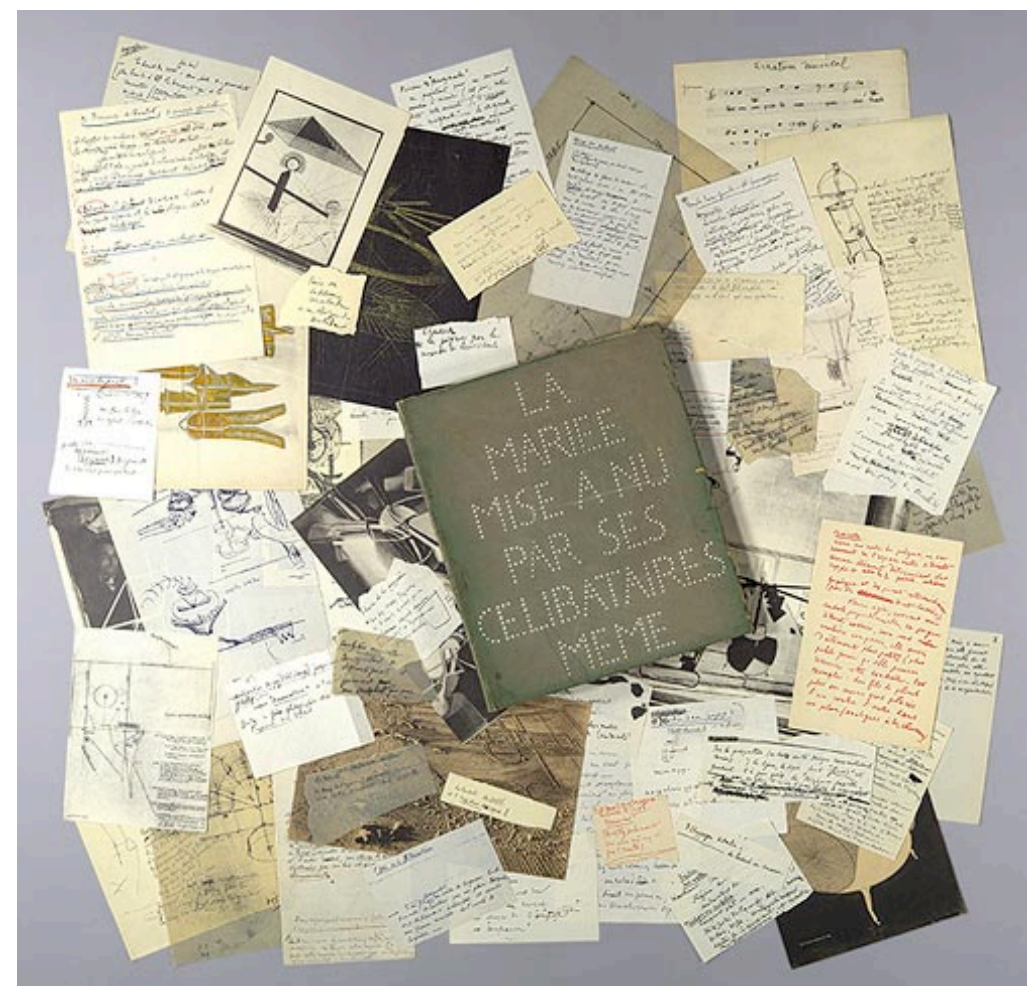

Figura 13: A Caixa Verde de Marcel Duchamp

Fonte: < http://www.metmuseum.org/toah/works-of-art/2002.42a-vvvv > acesso em 8 de outubro de 2014.

Outro trabalho que merece destaque é o "Livro llegível" do italiano Bruno Munari, criado entre as décadas de 1950 e 60. "O objetivo da experimentação foi ver se é possível usar o material com que se faz um livro como linguagem visual" (MUNARI, 1981, p:221). Ou seja, subverter o códice institucionalizado. 


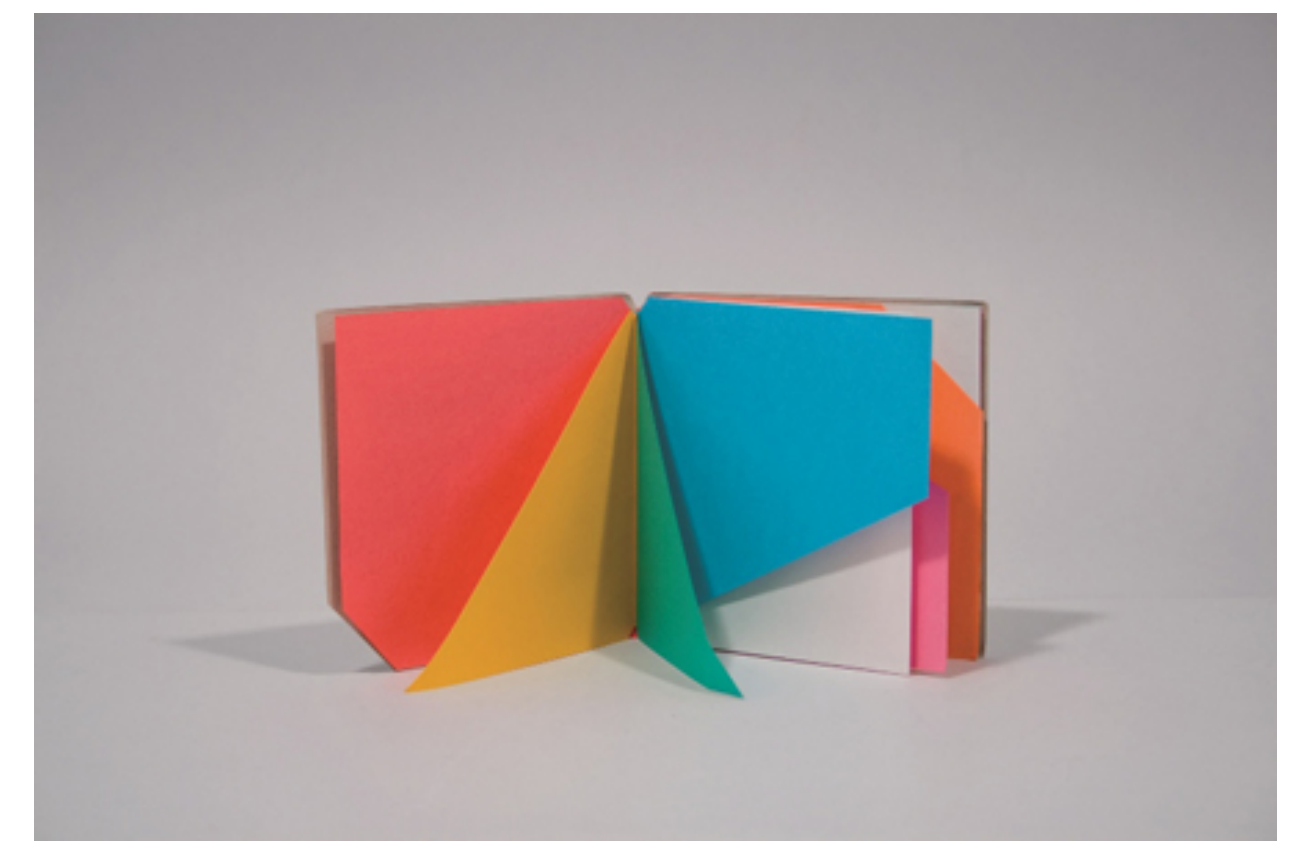

\section{Figura 14: Livro llegível de Bruno Munari \\ Fonte: < http://editora.cosacnaify.com.br/blog/?p=13372 > acesso em 9 de outubro de 2014}

Mas tal apresentação do campo ainda permanece superficial e pode acarretar confusão. Em busca de uma sistematização dos livros de artista e suas vertentes, Clive Phillpot cunha em 1982 seis definições. Nelas, já é possível assimilar mais especificidades e vislumbrar fronteiras, mesmo que tênues. São elas:

Livro: Coleção de folhas em branco e/ou que portam imagens, usualmente fixadas juntas por uma das bordas e refiladas nas outras para formar uma única sucessão de folhas uniformes.

Livro de arte: Livro em que a arte ou o artista é assunto.

Arte do livro: Arte que emprega a forma do livro.

Livro-obra (bookwork): Obra de arte dependente da estrutura de um livro.

Livro-objeto: objeto de arte que alude à forma de um livro.

Ainda com a estratégia de criar um método para aproximação, Phillpot apresenta um 
diagrama com essas definições formando um sistema. O esquema faz parte da segunda edição do catálogo da exposição Outside of a dog, sob curadoria do autor, lançada em 2004. Sua finalidade era distinguir os trabalhos participantes da mostra.

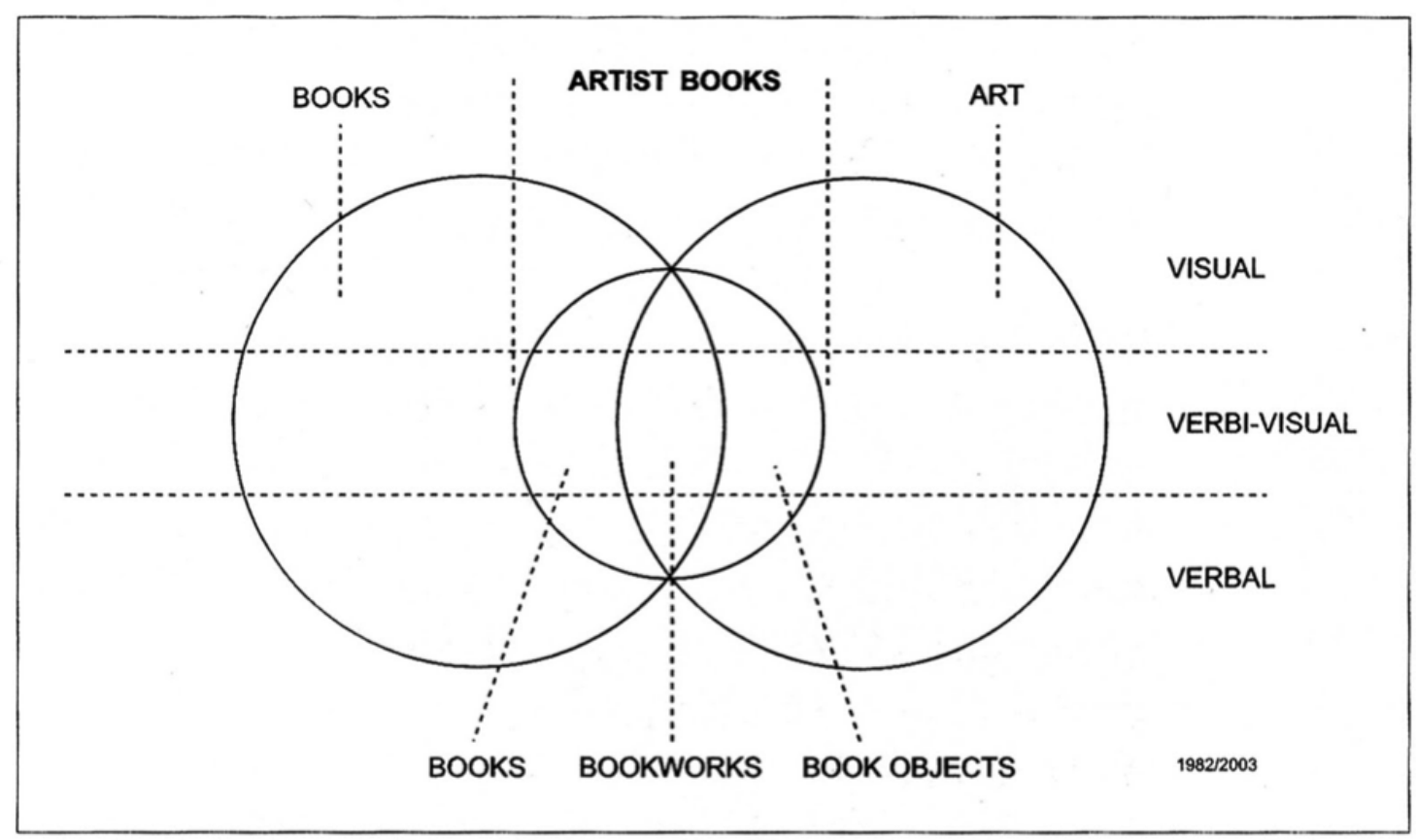

Figura 15: Diagrama de Phillpot

Fonte: < http://daskunstbuch.at/2012/10/15 > acesso em 9 de outubro de 2014

Três conjuntos são claramente demarcados: livro, livro de artista e arte. Eles possuem partes interseccionadas onde se encontram os livros-obra, livro-objeto e livros que apesar de se proporem à experimentação, continuam mais próximos da tradição. São traçados também parâmetros sobre a forma de expressão, sendo eles visual, verbo-visual e verbal.

Considerando aqui o recorte proposto para criação do livro Cartografia Materna, restrinjo a análise aos livros-objeto. Phillpot, partindo do diagrama, os caracteriza por criações artísticas, verbo-visuais mais distantes do livro enquanto códice institucionalizado. É um cruzamento em que forma e conteúdo se tornam um único corpo, adquirindo a capacidade de renovar o seu significado por meio dessa simbiose. 
Segundo Doctors (1994), o livro-objeto se configura nos vazios deixados pela literatura e artes visuais. Sua narrativa ganha novos contornos ao englobar a atmosfera plástica, partindo para um mundo onde é possível sobrepor, juntar e combinar elementos que pareciam impossíveis de unir.

Edith Derdyk (2012) afirma que a narrativa dos livros-objetos nasce cegamente da ponta dos dedos. Isso significa que ela nos convida a explorar os sentidos além do que estamos acostumados. Cada manuseio é uma experiência distinta. "Olhar, pegar, abrir, folhear, fechar, virar, vincar, furar, sobrepor, dobrar, ler, justapor, acumular, rasgar, costurar, atravessar, cortar, trocar, tocar" (Derdyk, 2012, p.171).

\footnotetext{
Até diria que um livro-objeto possui uma vocação musical - partitura espacial conjunção entre tempos e espaços gerando múltiplas leituras, em que cada leitor se torna um coautor do livro, corporificando a natureza de uma obra em aberto. Apesar de ser sempre uma leitura individual, assim o escrito torna-se um coletivo: um caldo coletivo de fruição (DERDYK, 2012, p.168).
}

Tomando proveito da capacidade de ultrapassar a mera utilização do texto verbal e imagens como elementos dissociados, parto para a busca de discursos não lineares convergentes. Evoco no produto o toque do tecido, a experiência de olhar por um monóculo, entre outras sensações. Cada fragmento tem a capacidade de agregar significado a outro. Uma foto pode conversar com determinado texto que, por sua vez, mantém relação com a estrutura que o acolhe. Uma cadeia de significados que se estende enquanto há fruição de um sujeito. O intuito do projeto é provocar o resgate da memória afetiva de quem o manuseia e fazer com que essa pessoa se coloque como parte da criação, que se lembre da mãe, da avó, da tia e de si mesmo. 


\section{Referências Bibliográficas}

ALMEIDA, Inês Leonor Costa. O Livro de Artista: Um Meio de Exploração Criativa. Lisboa: Universidade de Lisboa, 2012. Mestrado, Ensino de Artes Visuais, Universidade de Lisboa, 2012.

CHARTIER, Roger. Cultura escrita, literatura e história. Porto Alegre: Artmed, 2001.

CHARTIER, Roger. Os desafios da escrita. Tradução de Fulvia M. L. Moretto. São Paulo: Editora UNESP, 2002.

DOCTORS, Marcio. A fronteira dos vazios. Rio de Janeiro: CCBB, 1994.

DELEUZE, Gilles. Espinosa filosofia prática. São Paulo: Escuta, 2002.

DELEUZE, Gilles; GUATTARI, Félix. Mil platôs - economia e esquizofrenia, vol 1. São Paulo: Editora 34 Ltda., 1995.

DERDYK. Edith. A narrativa nos livros de artista: por uma partitura coreográfica nas páginas de um livro. Revista Pós, v2, n.3. Belo Horizonte: Universidade Federal de Minas, 2012.

GOMBRICH, Ernst Hans. Arte e ilusão: um estudo da psicologia da representação pictória. São Paulo: Martins Fontes, 1995.

GUATTARI, Félix. Caosmose: Um novo paradigma estético. São Paulo: Editora 34 Ltda., 1992. LAGE, N. A reportagem: Teoria e técnica de entrevista e pesquisa jornalística. Rio de Janeiro: Record, 2004.

LISPECTOR, Clarice. A descoberta do mundo. Rio de Janeiro: Rocco, 1999. LUCAS, Fábio. Prefácio. BRITO, José Domingos de. (org.) In: Literatura e Jornalismo. São Paulo: Novatec, 2007.

MIRANDA, Wander Melo. Corpos escritos. São Paulo: EDUSP; Belo Horizonte: Editora UFMG, 1992.

MUNARI, Bruno. Das coisas nascem coisas. Lisboa: edições 70, 1981.

PHILLPOT, Clive. Books, bookworks, book objects, artists' books. Artforum. New York. New York, v. XX, n.9, 1982.

PHILLPOT, Clive. Outside of a dog. ( Catálogo ampliado de exposição de mesmo nome), 2004. 